\title{
GÉNESIS Y DESARROLLO DEL CONCEPTO DE EVOLUCIÓN
}

\author{
HILDE SÁNCHEZ MORALES \\ Universidad Nacional de Educación a Distancia, Madrid
}

\begin{abstract}
RESUMEN: La teoría evolucionista de Darwin, en la fecha de la publicación de El origen de las especies (1859), atrajo inmediatamente la atención, pero no recibió unánime aceptación. Muchos la consideraron contraria a la ortodoxia religiosa y una amenaza que atentaba contra el orden ideológico tradicional. Otros la aceptaron con restricciones y otros la tomaron como verdad absoluta. Hay que reconocer que la opinión culta de la época victoriana era fuertemente conservadora y hostil a todo lo que se desviara de la ortodoxia. A esto hay que añadir que el planteamiento de Darwin violaba el concepto de Naturaleza hasta entonces reconocido; de tal forma que por parte de amplios sectores de la iglesia la reacción fue muy agresiva. Los debates y publicaciones acerca de este tema han cobrado especial visibilidad con motivo de la celebración, en el 2009, del bicentenario del nacimiento de Charles Robert Darwin.
\end{abstract}

PALABRAS CLAVE: Teoría evolutiva, Darwin, ortodoxia religiosa, concepto de evolución.

\section{Genesis and Development of the Concept of Evolution}

ABSTRACT: Darwin's evolutionary theory, on the date of the publication of On the Origin of Species (1859), immediately attracted the attention, but received unanimous acceptance. Many considered it contrary to religious orthodoxy and a threat that threatened the traditional ideological nature. Others agreed with restrictions and other taken it as absolute truth. Admittedly that the educated opinion of the Victorian Era was strongly conservative and hostile to anything that deviated from orthodoxy. To this we must add that Darwin's approach violated the concept of nature hitherto recognized; so that by broad sectors of the church's reaction ware very aggressive. The discussions and publications on this subject have become especially visible on the occasion of the celebration, in 2009 , the bicentennial of the birth of Charles Robert Darwin.

KEY WORDS: Evolutionary theory, Darwin, religious orthodoxy, concept of evolution.

\section{INTRODUCCIÓN}

...¡No hay a nuevo bajo el sol!

Libro de Eclesiastés (1.4)

Siglo III a.C.

Una de las características del pensamiento del hombre es su tendencia a repetir temas y debates. Entre los debates más enconados y permanentes es el que mantienen los partidarios de la interpretación darwinista de la evolución 
frente a los partidarios de la teología de la creación ${ }^{1}$ y, en la actualidad, la que sostienen con los seguidores del «diseño inteligente». Pensadores que hacen referencia a la idea de evolución ya los encontramos en tiempos remotos, pero fue Darwin quien presentó la idea con pretensiones de constituirla en verdad definitiva ${ }^{2}$. Los debates y publicaciones acerca de este tema han cobrado especial visibilidad con motivo de la celebración, en el 2009, del bicentenario del nacimiento de Charles Robert Darwin ${ }^{3}$.

La teoría evolucionista de Darwin, en la fecha de la publicación de El origen de las especies ${ }^{4}$ (1859), atrajo inmediatamente la atención, pero no recibió unánime aceptación. Muchos la consideraron contraria a la ortodoxia religiosa y una amenaza que atentaba contra el orden ideológico tradicional; otros la aceptaron con restricciones y otros la tomaron como verdad absoluta. Hay que reconocer que la opinión culta de la época victoriana era fuertemente conserva-

1 Entienden que las especies vivas están constituidas por seres fijos e inmutables surgidos de la voluntad y la mente de su creador.

2 Russel Wallace, A. (1823-1913), evolucionista que viajó por el Amazonas y por el archipiélago malayo llegó prácticamente a las mismas conclusiones que Darwin. Su teoría se la envió a Darwin en 1858. Presentaron conjuntamente, una comunicación en la Sociedad Linneana de Londres. Su obra Sobre la tendencia de las variedades a diferenciarse indefinidamente del tipo original (1858) se publicó junto con unas cartas y trabajos de Darwin. Ha sido una de las sincronías más singulares acaecidas en la historia de la ciencia.

3 Particularmente, en Estados Unidos los grupos creacionistas, creyentes en la verdad literal de la Biblia, siguen teniendo mucha fuerza. Ya a partir de los años veinte del siglo pasado intentaron impedir la enseñanza de la teoría de Darwin en las escuelas. Consiguieron que en varios Estados se promulgaran leyes prohibicionistas. En 1968, el Tribunal Supremo las declaró contrarias a la Constitución. Sin embargo, en 1980, estos grupos lograron sacar leyes en Arkansas y Luisiana que dictaminaban que el creacionismo se enseñaría como alternativa a la teoría de la evolución. Estas leyes han vuelto a ser declaradas inconstitucionales. El jesuita francés Pierre Teilhard de Chardin (1881-1955) buscó conciliar evolucionismo con cristianismo. Postuló que el orden natural no puede separarse de una idea finalista. En 1958, sus obras fueron declaradas fuera de la ortodoxia católica, pero el papa Pablo VI le rehabilitó y recientemente, Benedicto XVI, en sus Principios de teología católica, ha resaltado la influencia que tuvo en la elaboración del documento del Concilio Vaticano II Gaudium et Spes. En torno a 1987, encontramos una nueva forma de creacionismo en la denominada Teoría del Diseño Inteligente. Esta teoría se enfrenta con gran vigor a la Teoría de la Evolución. Cobró impulso con la creación, en 1990, del Discovery Institute y dentro de esta institución con el establecimiento, en 1996, del Center for Science and Cultura. Tiene su expresión teórica en el libro de Phillip E. Johnson, Proceso a Darwin (1991). Su argumentación se diferencia de la de los teóricos creacionistas en que la mayoría de los teóricos del Diseño Inteligente no esgrimen argumentos religiosos. Afirman que el universo está demasiado bien adaptado a la vida como para que se deba al azar o a causas de tipo material; de donde, su creación se debe a un agente inteligente, a un diseñador, del que no se conoce su naturaleza, ni sus motivaciones.

${ }_{4}$ El título completo de la obra en 1859 era El origen de las especies por medio de la selección natural o La preservación de las razas favorecidas en la lucha por la vida y, en su sexta edición, en 1872, fue acortado a El origen de las especies. En las primeras ediciones no empleó el término «evolución». Es en la sexta edición, en 1876, cuando aparece dicho término. Antes había utilizado la expresión «descendencia común con modificación». 
dora y hostil a todo lo que se desviara de la ortodoxia, a lo que hay que añadir que el planteamiento de Darwin violaba el concepto de Naturaleza hasta entonces reconocido; de tal forma que por parte de amplios sectores de la iglesia la reacción fue muy agresiva. Es significativa la controversia que tuvo lugar siete meses después de la publicación de El origen de las especies. La controversia tuvo lugar porque la Asociación Británica para el Avance de la Ciencia convocó una reunión destinada a discutir las teorías de Darwin. La disputa se suele describir como un choque entre religión y ciencia. En esta reunión estuvo presente Francis Galton (1822-1911), miembro de la Real Sociedad, que elogiaría sin reservas la teoría darwinista y se convertiría en un promotor de ella.

Como decíamos, la corriente creacionista (Ayala, 2007) fue de las primeras en disentir de la teoría darwinista. El creacionismo interpreta la historia de forma providencialista y sus argumentos apelaban no sólo a la Biblia, y señalaban que la teoría evolucionista adolecía del fundamento empírico que la hiciera convincente. A lo anterior hay que añadir que las aportaciones de Darwin, como ocurre con cualquier nueva idea, encontraron resistencias por parte de amplios sectores científicos porque, como dice René Dubos, «... si bien no hay quien pueda escapar a los efectos determinantes de su constitución genética, es casi igual de dif ícil escapar de la influencia condicionadora de las primeras experiencias culturales» (Dubos, 1976:18).

\section{LA TEORÍA DARWINISTA DE LA EVOLUCIÓN}

La teoría evolucionista darwinista proviene del campo de la Biología. Postula que todos los organismos sobreviven a través un proceso de selección natural, concepto que equipara al de Spencer de la «supervivencia de los más aptos»: «... Este principio por el cual toda ligera variación, si es útil, se conserva, lo he denominado yo en términos de selección natural, a fin de señalar su relación con la facultad de selección del hombre; pero la expresión, frecuentemente, usada por Mister Herbert Spencer de la supervivencia de los más adecuados es más exacta y es, algunas veces igualmente conveniente» (Darwin, 1980: 112). El concepto lo aplica en el sentido de lucha de los individuos por alcanzar los escasos bienes del medio, de tal manera, que sólo sobreviven y se reproducen los más adaptados ${ }^{5}$. En palabras del propio Darwin, «Se puede decir, metafóricamente, que la selección natural busca, en cada instante y en el mundo entero, las variaciones más ligeras; rechaza las que son nocivas, conserva y acumula las que son útiles; trabaja en silencio, insensiblemente, siempre y en todas partes, desde que se presenta la ocasión, a fin de mejorar todos los seres orgánicos con relación a sus condiciones de existencia orgánicas e inorgánicas» (Darwin, 1975: 51).

5 La obra de Darwin, junto con la teoría de la transmisión de los caracteres hereditarios de Gregor Mendel y la disciplina genética de poblaciones forman la síntesis de la moderna teoría de la evolución. 
La revolución generada por las aportaciones de Copérnico, Galileo y Newton $^{6}$ fue completada con la fórmula darwiniana. Estos científicos habían dejado fuera la explicación del origen y transformación de los seres vivos y la obra de Darwin encerraba el germen para desarrollar la idea de que el hombre, al igual que cualquier otra especie viva, era producto de la evolución biológica. Pero Darwin, en El origen de las especies, se abstuvo de incluir algún antepasado a los humanos, aunque sí alude al hombre cuando se refiere a las leyes que rigen la herencia. Afirma: «... Nadie puede decir por qué la misma peculiaridad en diferentes individuos de la misma especie o en diferentes especies es unas veces heredada y otras no; por qué muchas veces el niño, en ciertos caracteres vuelve a su abuelo, su abuela o un antepasado más $\mathrm{r}$ emoto; por qué muchas veces una particularidad es transmitida de un sexo a los dos sexos, o a un sexo solamente...» (Darwin, 1980: 54). Así, El origen del hombre (1871) incorpora un nuevo factor a la selección natural: «la selección sexual» por parte de las hembras, que eligen a los machos más fuertes para la reproducción. En esta segunda obra, realiza comparaciones muy explícitas y pormenorizadas entre las características del hombre y la mujer, y las extrapola a las que existen entre macho y hembra en los «cuadrumanos». Afirma: «He consignado las diferencias precedentes entre los dos sexos de la especie humana, porque son singularmente parecidas a las de los cuadrumanos...» (Darwin, 1995: 528-529).

En definitiva, el resultado de la aparición, en 1859, de El origen de las especies fue que Darwin rompió la cuasi-unanimidad existente en una comunidad científica que estaba en bastante buena armonía con los relatos creacionistas, que explicaban la historia del origen de la tierra, del hombre, de la vida y de su destino; y que sostenían que el mundo fue creado casi instantáneamente hace miles de años.

El período inicial de expansión y relevancia de la teoría tuvo lugar entre 1860 y 1900. Entre 1900 y 1930 perdió esta posición. Estos fueron años en los que la mayoría de los científicos impugnaron la teoría. Fue negada y abandonada. Sin embargo, no desapareció totalmente, algunos científicos mantuvieron la fe en los postulados darwinistas, tanto en el campo de las ciencias naturales como en él de las ciencias sociales. Al respecto, y a título de ejemplo, es de interés recordar, la famosa Sociología Genética, de Francisco Cosentini, con el subtítulo Sobre el pensamiento y la vida social prehistórica ${ }^{7}$. Cosentini ofrece una reelaboración del planteamiento darwinista al recoger la hipótesis del zoólogo ruso Kessler, de quien afirma: «... fue, después de Darwin, el pri-

6 Copérnico, Galileo y Newton habían explicado que los fenómenos naturales eran resultado de procesos naturales.

7 En España apareció en 1911, publicada por Daniel Jorro, Editor, y traducida por Antonio Ferrer y Robert, Abogado del Ilustre Colegio de Barcelona, quien dedicó la traducción a Don Gumersindo de Azcárate, que, según dice le inició en el estudio de la Sociología Genética.

8 Fiódorovich Kesser, K. (1815-1881), en 1879, expuso en un discurso la llamada «Ley de la ayuda mutua». Con ella quería corregir la teoría de Darwin. No estaba con forme con 
mero que consideró la ayuda como una ley natural y como el factor principal de la evolución» (Cosentini, 1911: 12) Pone el énfasis en «la ayuda» frente a la interpretación general de «lucha por la existencia». En rigor, utilizar el concepto sólo como "conflicto» es hacer una imprecisa aplicación. El propio Darwin, cuando se refiere a la «lucha por la existencia» (idea que toma de Malthus), lo hace en sentido general y metafórico: «Debo advertir que utilizo el término lucha por la existencia en el sentido general y metafórico, lo cual implica las relaciones mutuas de dependencia de los seres orgánicos y, lo que es todavía más importante, no sólo la vida del individuo, sino su aptitud y éxito en dejar descendencia» (Darwin, 1975: 10) y Sorokin, sobre este particular aclara, «... Darwin deja prácticamente indefinida su concepción de la lucha por la existencia. En su obra, usa el término en dos sentidos diferentes. El primero amplio, incluye todos los fenómenos de la «dependencia de un ser respecto de otro» (...), y todas las reacciones protectoras tales como ayuda mutua, sociabilidad, cooperación, etc. El segundo, en un sentido más estricto, significa principalmente «reacciones de lucha, de antagonismo y de hostilidad. Esta divergencia de los significados y el uso alternado de ambos, ha viciado considerablemente la teoría de Darwin» (Sorokin, 1951: 339).

Entre los años 1930 a 1950 se retoma la idea de evolución; en 1950 cayó en desuso y las críticas afloraban con facilidad. Pero la ciencia siempre busca explorar nuevos caminos, por ello promueve la actitud crítica-innovadora como fuente para lograr la vieja aspiración de «controlar» a través del conocimiento la Naturaleza y la realidad social. Por esta razón, me parece importante destacar que en el tema de la evolución, hoy, asistimos a una expansión de la idea. Iluminador para entender esta aseveración es señalar que, en recientes fechas, (marzo del 2011) la Revista Temas para el Debate (Revista Temas para el Debate, 2011) ha dedicado buena parte de su contenido al tema de la evolución, destacándolo en su portada con el título: Evolución humana, cultura y civilización.

En Alemania, la teoría darwinista prendió hondo. Ernst Haeckel (1834-1919) popularizó el trabajo de Darwin. No compartía en su totalidad las bases sobre las que se apoyaba la idea de la selección natural, pero sí creía en la evolución y fue uno de los primeros en extrapolar la evolución biológica a otros campos. Proclamó una correlación entre la evolución del organismo (ontogenia) y la evolución de las especies (filogenia), es lo que llamó «la ley fundamental biogenética». Frente a la teoría darwinista otorgaba papel importante al medio ambiente: «Alguna eficacia puede atribuirse a la acción directa y determinada de las condiciones externas de vida, y alguna a las costumbres; pero sería un temerario quien explicase por estos agentes las diferencias entre un caballo de carro y uno de carreras,...» (Darwin, 1980: 71). Haeckel creía que la selección

el postulado de «la lucha por la existencia», que, según afirma olvida la cooperación intraespecífica al centrarse exclusivamente en relaciones extra-específicas. Tampoco estaba de acuerdo con que la evolución actúa en los dos niveles: lucha y ayuda. 
era sobre todo resultado del contacto con el medio ambiente ${ }^{9}$ enunciaba que el proceso:1) tenía al hombre como meta final, 2) que todos los organismos procedían de una sola forma ancestral y 3 ) que los simios y los humanos tienen un origen común, existiendo entre ellos un «eslabón perdido».

En tiempos de la aparición de El origen de las especies, el progreso de las ciencias naturales y, en particular, de la Biología generaron una atmósfera científica que no tardó en dar lugar a una gran variedad de escuelas. Escuelas que han tratado de explicar todo cuanto hay en el universo, en el hombre y en la vida social de éste. Como dice Manuel Sales y Ferré «... Así, no bien la Biología fijó el concepto de organismo, con la célula por elemento, y formuló las leyes generales de ésta, pensadores de todas las tendencias aplicaron el uno y las otras a la sociedad... El hecho de aplicar la palabra organismo a la humanidad entera, muchas de cuyas partes no mantienen relación entre sí, revela la fuerza con que el nuevo concepto se impuso» (Sales y Ferre, 1912: 6-7). Y, queriendo encontrar paralelismos entre «la sociedad humana» $\mathrm{y}$ «lo orgánico», se tomaron conceptos de las ciencias naturales, particularmente de la Biología, realizando analogías con las que explicar el desarrollo de la sociedad.

\section{Precursores de la teoría de la eVolución y del biologicismo}

Las correspondencias entre «organismo» $\mathrm{y}$ «sociedad» no eran nuevas. Antecedentes a la interpretación de la sociedad, en términos analógicos entre la sociedad humana y el organismo vivo los encontramos ya en los Libros Sagrados de la India. En la antigua Grecia, el tema de que todo cambia lenta y continuamente ya lo plantearon los primeros pensadores. Heráclito (aprox. 535-484 a.C.) enseñaba que todo está sujeto a un eterno fluir; entendido éste como un proceso en cambio continuo que lo somete todo a nacimiento y destrucción. Especial interés despierta la figura de Anaximandro de Mileto (aprox. 610-545 a.C.), a quien muchos señalan como el primero en enunciar una elaborada teoría de la evolución. Sus escritos hablan de un proceso de cambio ordenado generador de las cosas que hace que se deriven unas de las otras a partir de un primer principio incondicionado, de una fuerza vital básica, infinita y en movimiento perpetuo.

Un principio que es desconocido, indefinido, ilimitado y básico, al que denomina el ápeiron («infinito») ${ }^{10}$, del que todo sale y al que todo vuelve. En su

9 Pensamiento que posteriormente fue desarrollado por Georges Vacher Lapouge (18541936) en su Teoría de la selección social. Teoría que sostiene que la acción directa de los agentes ambientales pueden modificar lentamente tanto los rasgos corporales como los mentales de una población.

10 El concepto ápearon ( «infinito»), introducido por Anaximandro, es algo diferente a lo hasta entonces expuesto. No lo identifica con los cuatro elementos: el aire, el agua, la tierra y el fuego. Designa una materia con carácter indeterminado, falta de cualidad, que se encuentra en eterno movimiento. El ápearon constituye la base de lo existente, es el principio. Es 
escrito aclara: «De donde las cosas tienen origen, hacia allí tiene lugar también su perecer, según la necesidad; pues da n justicia y (dan) pago unas a otras de la injusticia según el orden del tiempo» (Martínez Marzoa, 1975: 36). Diógenes de Apolonia (aprox. 460?-390 a.C.) continuó estos planteamientos. Platón (427347 a.C.) y Aristóteles (384-322 a.C.) presentan un mundo menos dinámico, sin embargo, establecen analogías orgánicas en sus obras. El hedonista Epicuro (341-270 a.C.) participaba de las ideas de vacío, movimiento, continuidad y transformación tal como se muestra en su Carta a Herodoto. Punto 4: «nada nace de nada, ya que si las cosas no tuvieran necesidad de semilla todo podría nacer de todo...»y, al referirse a los átomos mantiene que «... los átomos están animados de movimiento perpetuo...» (punto 8). El vacío no puede inmovilizarlos, además «... el movimiento de los átomos no ha tenido comienzo, ya que los átomos son tan eternos como el vacío».

Entonces, ¿cómo se origina la transformación? La respuesta la encuentra en el movimiento perpetuo de los átomos y en la fuerza propia que muchos de ellos poseen «... Unos están separados por grandes intervalos; otros, por el contrario, conservan su impulso todas las veces que son desviados, uniéndose a otros y convirtiéndose en las partes de un compuesto ». Consecuentemente, es el movimiento en el vacío y el propio impulso de los átomos el que genera la transformación, de donde se deduce que no «todos» se «transforman». Sólo se transforman los que "conservan su impulso». El poeta romano Tito Lucrecio Caro (99-55 a.C.), populariza las doctrinas de Demócrito y Epicuro al presentar su concepción mecanicista del cosmos en el poema De rerum natura ( Sobre la naturaleza de las cosas» $)^{11}$. Afirma que la Naturaleza se compone de dos principios: cuerpos y vacío. Concibe el universo como un conjunto fortuito de átomos (cuerpos) que se mueven eternamente en el vacío: «... / Pues movidos en medio del vacío/.../ El universo se renueva siempre/... (De Rerum Natura) ${ }^{12}$. El poema contiene una visible teoría de la transformación y renovación del «universo». Este punto de vista recoge las tesis transformistas de que las cosas no surgen de la nada y no pueden volver a la nada, sino que cambian en un proceso eterno y cósmico. El general y político romano Menecio Agripa (aprox. 63-12 a.C.), en su discurso («Fábula de Agripa»), realiza una equiparación entre la sociedad y el cuerpo humano; y expone, en términos orgánicos, el buen funcionamiento de la sociedad y las causas de sus males ${ }^{13}$.

inmortal, indestructible e imperecedero. El Diccionario soviético de filosofía (1965) recoge el término y lo define como «... materia infinita, indeterminada, exenta de cualidad y que se halla en eterno movimiento...»

11 De rerum natura. Poema literario traducido por José Marchena en 1791 y recogido por (Marcelino Menéndez Pelayo, M, 1892). Es considerada por muchos la obra más completa de física de la antigüedad.

12 De rerum natura, Libro I.

13 Esta fábula alcanzó gran difusión entre los historiadores (Livio, Dionisio de Halicarnaso, Plutarco, ...). 
El principio aristotélico de que «todo movimiento precisa un motor» fue la idea dominante hasta mediados del siglo XVI. Durante los siglos XVI, XVII y XVIII, debido a la Astronomía, la Geología y la Paleontología, resurgieron las viejas teorías evolucionistas y organicistas, se desarrollaron y se reinterpretaron. Se constituyeron en corrientes de pensamiento abriendo a la ciencia caminos que han llegado hasta nuestros días. Particularmente, en el siglo XVII la aparición de la física newtoniana modifica la idea de Naturaleza. Los Principia (1687) de I. Newton (1642-1727) proclaman que el mundo está regido por «leyes naturales». El cambio se deja sentir con fuerza en el siglo XVIII, momento en el que aparecen pensadores que extrapolando enunciados de la Física, entienden que si en la Naturaleza rigen leyes naturales en el mundo social rigen leyes sociales que explican la evolución sociocultural del hombre. Como dice R. Nisbert: «En el siglo XVIII había muchos pensadores que buscaban causas y leyes naturales que explicasen el devenir de la historia del hombre» (Nisbet, 1996: 259). Sus ideas se inspiran en los viejos filósofos. Se oponen a la versión bíblica de la creación y con su fe en la razón y espíritu crítico van terminando con las especulaciones metafísicas de siglos pasados divulgando las ideas de "evolución», «desarrollo» y «cambio». Como dice Edward O. Wilson: «Las grandes ramas del saber surgieron en su forma actual (ciencias naturales, ciencias sociales y humanidades) a partir de la visión unificada de la Ilustración generada durante los siglos XVII y XVIII» (Wilson, 1999:57). En Francia, donde las doctrinas de la Ilustración tuvieron su máxima expresión, en los escritos de sus pensadores, apenas aparece el término evolución; utilizan el concepto de «progreso» ${ }^{14}$. Cuando usan el concepto de "evolución» lo hacen en sentido orgánico. Por ello, se discutió mucho acerca de la «evolución de los organismos» y se planteó si la evolución tenía lugar por epigénesis o por ontogénesis.

\section{LA ILUSTRACIÓN: ANTECEDENTES DIRECTOS}

Parece oportuno aclarar que en el siglo xviii se investigan las causas generales que han conducido al desarrollo del conocimiento, del hombre y de las sociedades. Se formula una concepción lineal evolucionista sociocultural. En cuanto a sus figuras más representativas empezaremos por señalar a Turgot (1717-1781) y Condorcet (1743-1794). Ambos se anticiparon a formulaciones de los siglos xix y xx y no emplean el vocablo «evolución», pero coadyuvaron poderosamente a su difusión. Recogieron el tema de que la sociedad está en un proceso de cambio continuo y le añadieron la evidencia de que las ciencias y las artes progresan de forma tal que la humanidad avanza hacia metas mejores «... Todas las edades están encadenadas las unas a las otras por una serie de causas y efectos que enlazan el estado presente del mundo a todos los que

14 El progreso lo define Bury como la creencia en que «... la civilización avanzó, avanza y avanzará en la dirección deseable» (Bury, 1928: 2) 
lo han precedido... La marcha total del género humano, con alternativas de calma y agitación, de bienes y males, marcha siempre - aunque a paso lentohacia una perfección mayor» (Turgot, 1991: 36). Turgot establece paralelismos entre la historia del hombre y la Naturaleza «... En la naturaleza el cambio es siempre semejante al ciclo... de las generaciones de los animales o plantas. No hay diferencia cualitativa... En la historia, en cambio, se produce auténtica novedad y, sobre todo, estas novedades se acumulan...» (Turgot, 1991: XLIV).

Los presupuestos de Turgot los desarrollaría Condorcet, quien se esforzó por descubrir la ley natural causante del eterno cambio que acontece en la historia humana. La denominaron «ley del progreso»"15. La ley del progreso es específica y universal, y conduce a un eterno progreso del espíritu humano y del perfeccionamiento social. El interés primordial de todos los ilustrados era la progresiva ilustración de la humanidad. Ningún trabajo acerca del pensamiento del evolucionismo sociocultural quedaría cumplido sin señalar la obra de Condorcet Esquema de un cuadro histórico del progreso del espíritu humano. Trabajo publicado en 1795 donde relata la historia de la emancipación de la razón humana, desde la formación de las primeras agrupaciones humanas hasta su momento histórico. Apela a la historia porque entiende es el pórtico desde el que puede explicarse el presente y predecir el futuro. Muy notables son las aportaciones de I. Kant (1724-1804) y Pierre Simon Laplace (1749-1827), que en sus obras señalan una evolución cósmica. Singular importancia tiene la figura de Thomas Malthus (1776-1834). Su obra, Ensayo sobre el principio de población (1798), busca refutar la idea de progreso de los ilustrados. Toma como base el crecimiento de la población en Estados Unidos durante el siglo XVIII y mantiene que el equilibrio entre alimentos y población sólo se establece como lo hace la Naturaleza mediante la muerte (epidemias, hambre y guerras) o controlando el crecimiento de la población. La relación que establece entre los individuos es de competencia por la supervivencia y deviene en conflicto. Pero, Malthus no tuvo en cuenta el aumento de la productividad. En la primera década del siglo XIX, encontramos el trabajo de J. B. Lamarck (1744-1829). Pensador calificado por amplios sectores como autor de la primera teoría moderna de la evolución. En su Filosofía zoológica (1809) desarrolló una teoría evolucionista y expuso su «ley de la herencia de los caracteres adquiridos». Ley que, afirmaba, regía la evolución de los seres vivos. Lamarck estaba enfrentado a Georges Cuvier (1769-1832) y rechazaba la teoría de las catástrofes de este último. La teoría lamarckiana no pudo ofrecer pruebas empíricas, lo que motivó que la comunidad científica se «acercara» a Cuvier.

En esta enumeración de pensadores hemos dejado muchos nombres, pero, no podemos omitir la figura de Hegel (1770-1831), a quien, como señala Ferrater Mora,»... Es difícil considerar como «evolucionista» la filosofía de Hegel pero la insistencia hegeliana en el devenir y en el proceso contribuyó

15 Aunque no es exactamente igual, es el antecedente más directo de la ley de los tres estadios de A. Сомте. 
grandemente a la difusión de la idea de evolución» (Ferrater Mora, 1994). Hegel, teorizó acerca de que «todo» está sometido a un proceso dialéctico que gobierna tanto el desarrollo lógico del pensamiento como la marcha de la historia humana. Para eliminar dudas acerca de la participación de Hegel en la difusión de la idea de evolución, añadimos la consideración que ofrece Julián Marías «... También están en relación con el positivismo y el utilitarismo los pensadores ingleses que desarrollan la idea de evolución, de origen francés -Turgot, Condorcet, Lamarck-, pero acuñada filosóficamente por Hegel...» (Marías, 1978: 346). Por su importancia en la aparición del principio de evolución, añadiremos a uno de los padres de la geología moderna: Charles Lyell (1797-1875). Lyell, en sus Principios de geología (publicados entre 1830 y 1833) se oponía a la teoría de las catástrofes y utilizando observaciones geológicas se refirió a los mecanismos de la evolución geológica. Elaboró su propia teoría: la teoría de la uniformidad con la que sostenía que las fuerzas naturales que cambian la Tierra son las mismas en todo tiempo (erosión, terremotos, volcanes, etc.). Aplica su teoría al mundo orgánico. Supuso que habían existido dos períodos: creación y extinción, que eran resultado de los profundos cambios climáticos, y a los que muchas especies no pudieron sobrevivir, pero que fueron sustituidas por otras creadas por leyes naturales. Darwin afirmó que la lectura de esta obra había cambiado su forma de ver el mundo.

Podríamos citar más nombres, pero creemos haber ofrecido un cuadro del pensamiento evolucionista y biologicista que invadiría el siglo XIX.

\section{El eVOlucionismo EN EL SIGLO XIX}

En el siglo XIX, el evolucionismo biologicista se desarrolló con vitalidad. La teoría darwinista se fortaleció con los grandes avances que tuvieron lugar en las ciencias naturales, que se constituyeron en modelo para las ciencias humanísticas. En particular hay que resaltar los descubrimientos habidos en materia de Biología ${ }^{16}$. Muchos pensadores del mundo social adoptaron fórmulas tomadas de la Física y de la Biología, reformularon ideas y establecieron analogías entre sociedad y organismo vivo, entre cambio social y evolución biológica,...

Aparecieron teorías que explicaban el comportamiento humano y funcionamiento de su sociedad según supuestos de las ciencias naturales. La idea de evolución no podía ser una excepción. La aplicaron tanto al medio físico como a la razón humana, a la sociedad, a las condiciones económicas,...

16 Schleiden descubrió en 1838 la célula vegetal. En 1839, Schwann que la célula era el elemento primario del organismo animal; en 1843, Koellicker probó que el huevo es una célula y que de él surgen las partes del cuerpo animal. Comte no tuvo en cuenta estos hallazgos, pero sobre Herbert Spencer ejercieron mucha influencia. (FREYER, 1945: 73) El manuscrito más importante de la biología moderna, Las leyes de la herencia de Gregor Mendel, fue publicado en 1865 . 
La Filosofía y la Sociología no podían quedar al margen de estas corrientes, por lo que el encuentro de estas ciencias con la Física y la Biología gestó un vasto campo de hipótesis y escuelas ${ }^{17}$. Muchas de las primeras grandes figuras de la Sociología exploraron esta vía para construir la nueva ciencia ${ }^{18} 18$. Como dice Hans Freyer «... Las categorías del pensamiento biológico penetran, es verdad, hasta el cuerpo mismo de la Sociología, y ésta hace suyo, sobre todo, el concepto de organismo...» (Freyer, 1945: 68). Así, en los albores de la Sociología encontramos los nombres de Augusto Comte (1798-1857) y Herbert Spencer (1820-1903), que unieron presupuestos biologicistas y fisicistas, y establecieron paralelismos entre la sociedad humana y el organismo biológico. Además, siguiendo a Montesquieu, proponen leyes con las que explicar los cambios en la realidad social ${ }^{19}$. Pasan de la «idea de progreso» a la «idea de evolución» e interpretan el «progreso» como un proceso evolutivo que conduce al espíritu humano, los conocimientos y la sociedad desde una situación de estado primitivo a un estado desarrollado.

A. Comte está convencido de que la ciencia es el mejor instrumento para comprender y organizar la sociedad. Sus ideas están muy enraizadas con el momento de crisis que había roto el orden social de su tiempo. Sociedad de la que manifiesta era preciso reorganizar positiva y científicamente. Entiende la evolución de la ciencia positiva como sucesiva y ordenada, donde cada ciencia descansa en las anteriores, particularmente en la inmediatamente anterior, en el caso de la Sociología en la Biología ${ }^{20}$, por lo que la Sociología toma principalmente a la Biología como referencia. A la sociedad la entiende como un sistema orgánico pero colectivo; donde el hombre deviene en una abstracción «El espíritu positivo es... directamente social... Para él no existe el hombre propiamente dicho; sólo puede existir la Humanidad, ya que todo nuestro desarrollo es debido a la sociedad, ...» (Comte, 1943: 194). Para Comte la «unidad social primaria de la sociedad» es la familia, a la que sitúa entre la Biología y la Sociología y, a través de un lento proceso, de ella nacen los pueblos y más tarde las instituciones.

Además de servirse de la Biología, se fija en todo el material conocido y, con los resultados obtenidos por el resto las ciencias. Postula a la Sociología como la ciencia última y sintética, resultado necesario del progreso de los

17 Por ejemplo, Sorokin señala como principales escuelas biologicistas: «1) la interpretación biorganicista de los fenómenos sociales; 2) la escuela antroporracial; 3) la escuela darwinista de la lucha por la existencia; y 4) la escuela instintivista...» (SoroKIN, 1951: 211).

18 Recordemos que Saint Simon propuso para la actual Sociología el nombre de Física social o Fisiología social.

19 A partir de 1748, fecha de la publicación de Del espíritu de la leyes del Barón de Montesquieu (1689 a 1755), la búsqueda de leyes que explicasen la realidad era una constante admitida en todas las ciencias. Montesquieu dice respecto a que «... todos los seres tienen sus leyes: las tiene la divinidad, el mundo material, las inteligencias superiores al hombre, los animales y el hombre mismo». (Montesouieu, 1980: 51).

20 Ciencia que en los días de Comte se llamaba «Fisiología». 
conocimientos positivos $^{21}$. Afirma que al igual que en Biología es imposible explicar el órgano separado del organismo al que pertenece, tampoco las partes de la sociedad pueden entenderse separadas de ésta. No vacila en tomar algunos principios de la Física. Dirá: «... Las leyes a que se ciñe la ciencia, son de dos clases: estáticas o dinámicas, según que conciernan a la existencia o al movimiento» (Comte, 1943: 32), concluyendo que éstas también gobiernan el mundo social. Ambas fuerzas están dirigidas por una ley inmutable: la ley de los tres estadios «... que consiste en el paso necesario y universal de la humanidad por tres estados sucesivos.»(Comte, 1943: 127). Ley de la que afirma: «... me ha permitido explicar científicamente las grandes fases históricas, principales grados sucesivos de este invariable desarrollo, apreciando así el verdadero carácter general propio de cada una de ellas...» (Comte, 1943: 127). Esta ley tiene como meta alcanzar el advenimiento del más alto grado de vida positiva, en un doble sentido: mental y social. El proyecto de Comte busca una reforma universal y su sistema positivo termina en metafísica con su religión de la humanidad. Herbert. Spencer (1820-1903) es el continuador más reputado del positivismo de Comte. No acepta de éste la ley de los tres estadios, la jerarquía de las ciencias y su modo de enfocar el proceso evolutivo pero en muchas otras cuestiones coinciden. Las teorías de Spencer han sido objeto de los más diversos juicios. Lo encontramos dentro de la corriente del «darwinismo social» (Martindale, 1968) y 191-192)22 pues se anticipó a Darwin en algunas ideas, como es la de la supervivencia de los más aptos, pero Spencer no la aplica exclusivamente en términos biológicos a la vida del hombre. Sin embargo, habla de razas inferiores, cuando se refiere al grado de evolución del hombre. Por ejemplo, dice:»... La completa formación de un cerebro mayor, que retarda la madurez del hombre respecto a la de los mamíferos, retarda también la del hombre civilizado respecto al salvaje...» (Spencer, 1957:34). En otras ocasiones, lo hallamos incluido en el «evolucionismo social», otras veces, dentro del «organicismo positivista», lo cierto es que él mismo incurre en contradicciones que coadyuvan a que no exista unanimidad a la hora de clasificarlo.

21 «La combinación de la ley de los tres estados y la clasificación de las ciencias tiene como fin demostrar que el modo de pensamiento que ha triunfado en matemáticas, en astronomía, en física, en química y en biología debe imponerse finalmente en el ámbito político y desembocar en la constitución de una ciencia positiva de la sociedad, que es la Sociología....» (ARON, 1976: 93)

22 Don Martindale (Martindale, 1968), en las páginas 191-192 lo sitúa dentro de la corriente darwinista; pero, en páginas anteriores (76 a 81) le presenta como un organicista social que, a pesar de establecer analogías entre la sociedad y el organismo vivo, cuida de explicar las diferencias que entre ambos existen. Manuel Sales y Ferré lo posiciona entre los nombres de la línea que denomina Sociología biótica, y afirma que está constituida por Comte, Schoeffle, Spencer, Liliendfeld y Works; diciendo que consideraron «a la sociedad exactamente como un organismo, por más que algunos antepusieran a este término el prefijo «supra», para expresar que realiza un grado de complejidad superior al del organismo individual, y se le aplicó toda la tecnología biológica de células, tejidos, órganos, aparatos, cerebro y aun de alma» (Manuel Sales y Ferré, 1913: 7) 
El evolucionismo de Spencer debe ser comprendido desde la influencia que sobre él ejercieron ideas provenientes de Lamarck, de la Física y de la Biología. Queremos destacar la influencia que sobre él ejerció la lectura de la obra Sobre la historia del desarrollo de los animales del naturalista, Kart E. von Baer (17021876), quien mantenía que: «...la serie de cambios experimentados por todo organismo durante su desarrollo embriológico, se presenta como el tránsito de una estructura homogénea a una estructura heterogénea...» (González Seara, 1976: 52). En sus planteamientos formula conceptos mecanicistas, biologicistas y establece analogías entre la sociedad y el organismo. A pesar de esto, según Hans Freyer, sus analogías biologicistas, quedan en eso: «... Spencer percibe exactamente que la Sociología no puede trabajar dogmáticamente con conceptos biológicos. El mismo alude a los rasgos en que se diferencian las formas sociales de las orgánicas,...» (Freyer, 1945:74). Es consciente de que concurren otros factores que determinan el comportamiento social del hombre. Así, en sus Principios de Sociología se refiere a la existencia de "factores originales» $\mathrm{y}$ «factores secundarios» que desempeñan un papel importante en la evolución pues «... favorecen o impiden las acciones sociales» (Spencer, 1947: 18). Proclama que con la inteligencia (factor intrínseco) nace el lenguaje, las herramientas, la cultura, el sentido de cooperación,... todo lo cual interviene en la posibilidad de «supervivencia». Spencer introduce en el hombre primitivo el pensamiento lógico racional pero entiende que para que se desarrolle tiene que evolucionar. En nuestros días, José Antonio Marina se inspira en esta idea del papel de la evolución de la inteligencia y publica un artículo en la Revista Temas para el Debate al que titula «Evolución, cultura y condición humana» (Revista Temas para el Debate, 2011: 29-32).

Spencer tenía empeño por encontrar leyes naturales con las que explicar el mundo social. Formula su famosa ley de la evolución (Gaupp, 1930: 149-151) ${ }^{23}$, que recorre toda su obra y mantiene que: «... Hay tres clases de evoluciones. La inorgánica comprende la astrogenia y la geogenia. La orgánica los fenómenos físicos y psíquicos de los «agregados viviente». La evolución superorgánica los agregados sociales...» (Spencer, 1947: 15). La evolución social aparece como la última fase del un proceso. Con estos planteamientos formula su ley de la evolución, que dice es «...una integración de la materia y una disipación concomitante del movimiento, durante los cuales la materia pasa de una homogeneidad indefinida e incoherente a una heterogeneidad definida y coherente, y el movimiento que subsiste experimenta una transformación paralela...« (Gonzalez Seara,1976: 51). El razonamiento es como sigue: tras la integración de la materia emerge una fase de diferenciación, que convierte la materia en un complejo

23 «... A esta ley llega mediante una serie de sucesivas inducciones, pero, a la vez, es posible deducirla de tres leyes naturales: la persistencia de la fuerza, la ley de la inestabilidad de lo homogéneo y la de multiplicación de los efectos y la de segregación de lo homogéneo» (Отто Gaupp, 1930). 
de partes distintas y conexionadas ${ }^{24}$. Esta explicación de la evolución era diferente de la ley del progreso de los ilustrados, de la evolución de Darwin y de la ley de los tres estados de Comte. En el caso de Spencer la ley no es lineal. En estos términos lo explica N.S. Timasheff, al referirse a la teoría de Spencer «... El progreso de un organismo social hacia estructuras más heterogéneas y más definidas se prosigue sólo mientras siguen operando las acciones que producen esos efectos...» (Timasheff, 1961: 53). La ley de la evolución la completa con la ley de la disolución, en un proceso donde, tras la disolución, el movimiento retenido vuelve a iniciarse. En ella domina la omnipresente idea de la «persistencia de la fuerza», por lo que no puede permanecer eternamente en estado de equilibrio ${ }^{25}$. Estas leyes están regidas por la «ley del ritmo». Sus supuestos muestran diferencias con la evolución planteada por Darwin. Para Darwin la evolución era irreversible, para Spencer no, por lo que puede detenerse, retroceder y volver a comenzar. La ley de la evolución de Spencer sufrió falsas interpretaciones. Se la acusó de linealidad. Al respecto dice Morris Ginsberg (1889-1970) «La más superficial observación de los hechos refuta la noción de desarrollo lineal y uniforme» (Ginsberg, 1961: 200). En conclusión, Spencer toma como modelos la Biología y la Física para seguir el rastro de la evolución, pero, en lo que a la Biología concierne, «Spencer no se ha acercado al problema de la evolución como Wallace y Darwin, desde el punto de vista biológico. ...» (Gaupp, 1930: 80). De manera semejante opina Luis González Seara, quien dice: «Es un error, por tanto, suponer que la teoría de la evolución de Spencer es un desarrollo, aplicado a la sociedad, de la doctrina de Darwin...» (González Seara, 1976: 52).

Tan diversos juicios como la teoría de Spencer ha recibido se deben a que él mismo cae en contradicciones al establecer analogías biológicas para el estudio del fenómeno social y terminar su planteamiento en el individualismo. Por ello, Francisco Giner de los Ríos (1839-1915) no interpreta este particular como contradicción, «... Pero cuanto dista aún de su desenvolvimiento y apogeo la doctrina que considera al organismo social como un ser, y aun como una persona, lo prueba el ejemplo de Spencer..., que saca de esa doctrina conclusiones individualistas,...» (Giner de los Rios, 1923: 44). Es más, Spencer censura en sus Principios de filosofía «A las antiguas teorías de Platón y a las modernas de Hobbes de haber descendido demasiado al pormenor en su comparación de la sociedad con el cuerpo humano, o con un organismo físico cualquiera...», (Giner de los Ríos, 1923: 82). Sorokin mantiene que Spencer lo que busca es

24 La fórmula de Lamarck que define la evolución como el transito de lo simple a lo compuesto está en la base de este planteamiento.

${ }_{25}$ Desde que en 1687 Newton formulara en sus Principia las tres leyes del movimiento, entre ellas el efecto de la «acción» «reacción», la conservación de la cantidad de movimiento era una verdad indiscutida. Como dice E. O. WiLson: «Las leyes de la física son en realidad tan exactas que trascienden las diferencias culturales... No hay en ellas espacio para variaciones...» (WILSON, E. O., 1999: 74). 
«... sostener la descentralización, el individualismo, el liberalismo, y una restricción de la interferencia gubernamental» (Sorokin, 1951: 229).

Lo que no se puede negar es que para Spencer el individuo es la base del agregado social. El siglo xx le rechazo, sin embargo, su influencia no ha desaparecido y en el pensamiento social norteamericano ha ejercido un gran impacto.

La influencia de Comte y Spencer ha sido grande. Sus seguidores han realizado distintas interpretaciones. Tal es el caso del francés E. Durkheim (18581917), del alemán F. Tönnies (1855-1909), del norteamericano Lewis Henry Morgan (1818-1881), del británico John Ferguson McLennan (1827-1881), del suizo Johan Jacob Bachofen (1815-1887), del británico Henry Maine (18281881), del británico Edward Tylor (1832-1917), etc.

\subsection{El Darwinismo Social}

En el último cuarto del siglo xix el triunfo del evolucionismo y de Darwin era absoluto. Entre las escuelas que emergen aparece una forma que confunde la Biología con la Sociología. Este enfoque sociológico enlaza con la escuela antropológica racial y desemboca en el racismo: se trata del «darwinismo social». Sus seguidores se apoyan en los dos pilares del evolucionismo de Darwin: la selección natural y la mutación genética; a esto hay que sumar la interpretación de antagonismo y hostilidad con que utilizan las ideas de la lucha por la existencia y la supervivencia de los más aptos. Admiten que todos los hombres tienen inteligencia, pero que en algunos permanece sólo en potencia, de forma tal que sólo los más capaces la poseen en plenitud. Hablan de razas superiores y razas inferiores..

El primero en formular una teoría aplicando los principios de la selección natural fue el inglés Walter Bagehot (1826-1877). Su obra más importante es Física y Política, donde se pregunta cuáles son las ciencias que pueden mostrar el origen de las sociedades políticas y el desarrollo de la vida primitiva. Niega la fuerza del «progreso» si no va acompañada de la selección natural, y afirma que «... La diferencia entre el hombre no civilizado y el civilizado es la misma que existe entre lo animales silvestres y los domesticados...» (Timasheff, 1961: 84).

Para otro darwinista, como es el caso de Ludwig Gumplowicz (1838-1909) la evolución social es producto de la lucha entre grupos, en la que se expresa la supervivencia de los individuos más aptos. Otros representantes de este movimiento los encontramos en las figuras de Arthur de Gobineau (1816-1882), P. Lilienfeld (1829-1903), A. Schäffle (1831-1903), William Grahan Sumner (1840-1910), J. Novicow (1849-1912). Este último afirma: «Desde el momento en que la sociedad está compuesta de seres vivos, no puede ser sino un ser viviente» (Sorokin, 1951: 223). Houston Chamberlain (1855-1927), Georges Vacher de Lapouche (1854-1936) explican la sociedad como una clase especial de organismo biológico. (Sorokin, 1951: 218-219). El propio Alfred Fouillée (1838-1912) no quedó libre de esta corriente. En su Psicología de los pueblos europeos afirma: «... si un individuo pertenece a una raza humana manifiestamente inferior o degenerada, será todavía susceptible de cierta educación; pero 
la conformación nativa de su cerebro le prohibirá todo desarrollo que exceda de ciertos límites...» (Fouillée, 1903: 18). Como vemos, el filósofo de «las ideas fuerzas» reconoce la existencia de «razas inferiores» que poseen una «conformación nativa de su cerebro» que no le permitirá mayor desarrollo. Con esta cita de un pensador no darwinista hemos querido ejemplarizar la fuerza que este movimiento alcanzó a finales del siglo xIX.

En resumen, el darwinismo social significa una identificación de «lo biológico» con «lo societario». Supuso la glorificación de la selección natural y la creencia en la existencia de hombres y sociedades superiores por naturaleza. Ante esta identificación entre «lo societario» y «lo biológico» queremos dar respuesta adhiriéndonos a las palabras de Sorokin cuando afirma: «Desde el momento en que el hombre es un organismo, las leyes de la biología le son aplicables, pero de esto no se sigue que toda la sociedad humana sea un organismo biológico.» (Sorokin, 1951: 227).

\section{El Siglo XX Y EL EVOlUCIONISMO}

El siglo xx ha asistido a la apertura de nuevos campos de investigación y a la proliferación de nuevas ciencias. En cuanto a la idea de evolución, en la década de 1940, un evolucionismo «revisado» reapareció. Fue a partir de 1945 cuando los científicos se dedicaron con más empeño a elaborar y a retomar teorías evolucionistas. La teoría darwinista recibió nuevos enfoques. A esta etapa se la denomina «neoevolucionismo». Entre sus figuras más eminentes cabe destacar al norteamericano Leslie White (1900-1975) que se mostró muy interesado en la idea de evolución. Planteó que el proceso evolutivo operaba como consecuencia de la lucha del hombre con el medio ambiente para obtener recursos y perpetuar la especie. En 1959, publica una de sus obras más conocidas: La evolución de la cultura: el desarrollo de la civilización hasta la caída del imperio romano. Otro continuador de esta línea es el estadounidense Julián Steward (1902-1972). Difiere de White en que no enfoca sus estudios en cómo evolucionan las culturas particulares. Realza el papel que los avances de la tecnología desempeñan en la evolución de las diversas culturas.

\subsection{La Sociobiología}

Las aportaciones al evolucionismo del biólogo Edward O. Wilson (1929) son en sumo grado genetistas. Sus obras más conocidas son: Sociobiología, La nueva síntesis (1975), Sobre la naturaleza humana (1978), Consilience. La unidad del conocimiento (1998) y La conquista social de la tierra (2012). Es el creador de la Sociobiología y del término «biodiversidad». Su obra es un intento de explicar la evolución animal y humana en términos darwinistas. Mantiene hipótesis que nos retrotraen al darwinismo social del siglo XIX. Ello se infiere de la definición que ofrece de la Sociobiología: «... el estudio sistemático 
de las bases biológicas de todo comportamiento social. De momento, centra su interés en sociedades animales... Pero esta disciplina también está interesada en el comportamiento social del hombre primitivo y en sus características de adaptación y organización dentro de las sociedades humanas contemporáneas, más primitivas» (Wilson, E.O, 1980: 4). A la Sociobiología la enmarca dentro de la Biología, porque entiende que el comportamiento del hombre está sujeto a las mismas leyes biológicas que dirigen el comportamiento animal general26: «... En esta visión macroscópica, las humanidades y las ciencias sociales se reducen a ramas especializadas de la biología: historia, biografía y ficción son los protocolos de investigación de la etología humana; y la antropo logía y la Sociología juntas constituyen la sociobiología de una sola especie de primates» (Wilson, 1980: 564). Niega el carácter estructural de las instituciones sociales y explica el comportamiento social humano bajo el prisma de la Etología y de la selección natural, a la que atribuye como fin último la reproducción y la multiplicación. Para él, el motor de la selección natural humana se encuentra en los genotipos: « los genotipos más aptos son aquellos que dejan más descendientes, los cuales y gracias a la herencia, se parecen a sus antecesores y los genotipos que dejan más descendientes presentan una mayor aptitud darwiniana. (Wilson, 1980: 69-70). ¿Cómo entiende la «evolución social»?. La interpreta como «... el resultado de la respuesta genética de la población a la presión ecológica, dentro de las limitaciones impuestas por la inercia filogenética...» (Wilson, 1980: 33). Así, la supervivencia dependerá de los genes, de tal manera que su éxito es éxito reproductivo. Éxito que es producto de la competencia entre genes. La clave está en los genes. De esta forma la lucha por la vida se convierte en «la lucha por la supervivencia genética» y el gen "ganador» pasará a la siguiente generación; y la transferencia se realiza por medio de la "herencia genética». En cuanto a la «selección natural», afirma,: «...es el proceso mediante el que ciertos genes preponderan en las generaciones siguientes sobre otros genes situados en la misma posición del cromosoma» (Wilson, 1980: 566). De este planteamiento se desprende que en la «supervivencia de los más aptos» sobreviven los individuos con genes más seleccionados. Como vemos, a diferencia de Darwin, no es entre los individuos donde se entabla la lucha, sino entre los genes: «La hipótesis a considerar entonces es que los genes que promueven la flexibilidad del comportamiento social se seleccionan intensamente a nivel de individuo...» (Wilson, 1980: 566). Ante estas aseveraciones es necesario preguntarse: ¿cuándo un individuo no puede procrear nos hallamos ante un individuos no adaptado, cuyo destino es desaparecer?

26 De la Sociología dice que «... en sentido estricto, es el estudio de las sociedades humanas en todos los niveles de complejidad y aún constituye un ente separado de la Sociobiología a causa de su enfoque primordialmente estructuralista y no genético» (Wilson, 1980: 4).

Y en Consilience afirma «La Sociología contemporánea se separa aún más de las ciencias naturales que la antropología... Gran parte de la Sociología moderna utiliza las medidas exactas y el análisis estadístico..... Muchos son, en expresión de Ellis, biofóbicos: temen la biología y están decididos a evitarla...» (Wilson, 1980: 274). 
Postula la existencia de genes egoístas y genes altruistas. Los primeros favorecen la supervivencia del organismo individual y los segundos crean actitudes cooperativas que permiten la aparición de la sociedad, la cultura y la socialización. De la socialización dice que: «... puede ampliar las variaciones en el comportamiento individual basadas en la genética,...» (Wilson, 1980: 134). A la sociedad la define como «... grupo de individuos pertenecientes a la misma especie y organizados cooperativamente...» (Wilson, 1980: 7). Consustancial con estos planteamientos es su concepción de «población»: «... Esta unidad, la más básica pero también una de las más empleadas con menor precisión en Biología evolutiva, está definida en términos de continuidad genética...» (Wilson 1980: 9). Este apelar a la Biología para explicar no sólo el comportamiento animal, sino también «lo humano» y «lo social humano», incluso lo encontramos cuando se refiere a la cultura en la crítica que realiza a los científicos sociales: «... los científicos sociales no han sido nunca (...) capaces de encajar sus narraciones en las realidades físicas de la biología humana y de la psicología, aunque con certeza es de aquí, y no de algún plano astral, de donde ha surgido la cultura» (Wilson, 1999: 269-270). Según lo anterior, la cultura tiene su origen en los genes. En todas sus explicaciones otorga primacía a los genes. La cultura es un producto del cerebro humano; y el cerebro está estructurado genéticamente. Está ligazón entre mente y cultura da lugar a «coevolución entre los genes y la cultura» (Wilson, 1999: 187), de forma que la cultura se convierte en una importante «pieza» en la evolución pues «... prácticamente todo el comportamiento humano es trasmitido por la cultura...» (Wilson, 1999:186). Los cambios de comportamiento pueden deberse a la cultura, pero ésta actúa como resultado de un cambio de frecuencias genéticas dentro de la población, con lo que evoluciona tanto el organismo como la sociedad.

Su obra Consilience. La unidad del conocimiento supone una continuidad de la Sociobiología. La gran sintesis. Afirma la unidad de la cultura y de las ciencias sociales con la Biología evolutiva. Sostiene que: «... una vez terminó la era de los pioneros, los teóricos se equivocaron al no incluir la biología y la psicología» (Wilson, 1999: 271). Aclara su formulación diciendo: «... Dentro del amplio terreno intermedio entre el modelo de la ciencia social normalizada y el determinismo genético, las ciencias sociales son intrínsecamente compatibles con las ciencias naturales» (Wilson, 1999: 277). A la propiedad que da unidad al conjunto del conocimiento científico la denomina "consiliense». Término que, como él mismo declara, toma de la Historia de las ciencias inductivas (1840) de William Whewell (1794-1866).

En su libro La conquista social de la tierra da un paso más allá y plantea que la «selección de grupo» es el único modelo que puede explicar el origen del hombre, su dominación, y su posterior conquista del planeta, cobrando especial valor la idea de que somos una especie «eurosocial», que está constituida «... por miembros de grupos que contienen múltiples generaciones y que están dispuestos a realizar actos altruistas como parte de su división del trabajo... Los lazos se basan en la cooperación entre individuos o grupos que se conocen 
unos a otros y que son capaces de distribuir propiedad y nivel social sobre una base personal» (Wilson, 2012: 31).

Su teoría contó desde el comienzo con adeptos y a pesar del gran predicament o que tiene en la comunidad científica, también es objeto de numerosas críticas. Sus propios colegas de Harvard le criticaron al ver que establecía paralelismos entre las sociedades de insectos, de mamíferos y del ser humano, así como por haber dedicado el capítulo final de su Sociobiología. La gran síntesis al ser humano como animal social por excelencia. Así pues, a pesar de tantos premios como ha recibido, su teoría ha sido tachada de especulativa, reduccionista, de negar la libertad al hombre, de retrotraernos al darwinismo social,.... Pero, en cualquier caso nos encontramos con un ferviente evolucionista. El mismo lo declara: «... descubrí la evolución. De repente (...), vi el mundo de una manera totalmente nueva... Estaba subyugado, no podía dejar de pensar en las implicaciones que la evolución tenía la clasificación y para el resto de la biología. Y para la filosofía, y para casi todo. La estructura estática se deslizaba hacia un proceso fluido...» (Wilson, 1999: 10). Declaraciones que dan idea de la fuerza que el concepto de «evolución» encierra. El intento de explicar el comportamiento humano con los mismos parámetros que para una especie animal estaba precedido por otros trabajos. A modo de ejemplo, señalamos el trabajo del zoólogo y etólogo británico Desmond Morris (1928), que en 1967 publicó El mono desnudo ${ }^{27}$, donde expone el comportamiento del hombre, desde una óptica zoológica y su evolución a partir del desarrollo del cerebro.

\section{CONCLusiones}

La larga historia que encierra el concepto de «evolución» nos ha obligado a enraizarlo con la más vieja tradición donde se ha "solidizado» la reflexión sobre este concepto; porque, como dice Wilson: «... Gran parte de lo que pasa por teoría social es todavía esclava de los grandes maestros originales...» (Wilson, 1999: 269) e incluso «esclava» de textos antiguos que con imágenes muy ilustrativas, representan la idea de que el mundo cambia y se transforma continuamente. La antigüedad de la idea de evolución podemos asimilarla al planteamiento de H. Freyer cuando dice: «Desde que son capaces de pensar, los hombres han meditado probablemente sobre los problemas de su convivencia. De igual manera han filosofado también sobre el Estado y la sociedad...» (Freyer, 1945: 35). Lo mismo podemos decir nosotros sobre la idea de evolución, que con uno u otro término: «transformismo», "progreso», «desarrollo»,... encontramos desde la Paleontología hasta la Sociología. La idea de evolución está

27 EDWARD O. Wilson afirma que: «... el hombre moderno es un "mono desnudo". El pelo se ha perdido en la mayor parte del cuerpo... Una explicación plausible es que la desnudez sirva de mecanismo para la refrigeración del cuerpo durante la extenuadota persecución de la presa, en las calurosas llanuras africanas...» (WILson, 1980: 564). 
estrechamente vinculada al movimiento, en el sentido que le aplica la Física; esto es como "movimiento perpetuo» tras haber recibido un impulso. Esta era la principal cuestión que se plantearon los primeros pensadores. Como tal movimiento, las preguntas que surgen son cuestiones tales como ¿hacia dónde va la humanidad?, ¿cuál es el principio determinante del cambio social?, ¿hacia dónde se dirige la sociedad?,... Para responder a estas preguntar se ha estudiado al hombre, su comportamiento, su sociedad,.... Es preciso advertir que la idea de «cambio» hay que diferenciarla de la de «evolución». El cambio no significa necesariamente "evolución». La «evolución» no es posible sin cambio, pero el «cambio» no es necesariamente evolutivo.

El concepto, en su utilización en las ciencias del hombre, ha dado lugar a teorías diversas y hasta contradictorias. Nosotros sólo hemos ofrecido algunos enfoques. Nos hemos detenido en su vertiente filo-socio-biologicista. Hemos adoptado este criterio porque su impacto fue especialmente fuerte en el campo de las ciencias sociales y su influencia sobre estas ciencias ha sido grande. Igualmente, no hemos querido olvidar tampoco a la Física, de la cual muchos de sus principios han sido adoptados.

De lo que no cabe duda es que el concepto de «evolución» constituye una de esas «ideas-fuerza $»^{28}$, muy útiles por la potencia y racionabilidad que encierran. El hombre las utiliza en su afán por controlar el presente y devenir no sólo de la Naturaleza, sino también de la sociedad humana y del propio hombre. La empresa es inalcanzable. El hombre la persigue sin cesar y, que duda cabe, ha logrado importantes triunfos. Pero, lo que siempre está en movimiento es inalcanzable; siempre va «por delante». Como dice René Dubos: «... en realidad no pueden sobrevivir sociedades estáticas, pues tienen que trastornarse y desmoronarse en un mundo donde todo cambia y se mueve sin cesar» (Dubos, 1976: 52). Particularmente el mundo del hombre encierra más dificultades de comprensión que el de la Naturaleza. Siguiendo W. Dilthey en Introducción a las ciencias del espiritu (Dilthey, 1949), en el mundo de los fenómenos naturales la comprensión de éstos se deriva de la fórmula «causa-efecto». En el mundo del hombre entre la causa y el efecto se introduce la «voluntad» y con la voluntad la «libertad». Por ello la fórmula se complica: «causa-voluntad-efecto. De acuerdo con el planteamiento kantiano el mundo del hombre es el «mundo de la libertad». De lo que se sigue que encontramos variados planteamientos, desiguales $\mathrm{y}$, muchas veces, contradictorios. A la sociedad humana unas veces la entienden igual/o como un "organismo» que evoluciona por impulso de su propia naturaleza o por el concurso de factores externos. Otras veces la conciben como un "mecanismo», creado merced a un "contrato social» establecido por voluntad del propio hombre, que la cambia de un estado a otro. En otras ocasiones se busca hacer una síntesis entre el «organismo» y el «mecanismo»,

28 Concepto creado por Alfred J. E. Fouillé y que da título a sus obras: L'Evolutionnisme des idées-fuerzas (1890), La Psycholologie des idées-fuerzas (1893) y La Moral des idées-fuerzas (1907). 
como es el caso de A. Fouillée, que elabora una teoría denominada «organicismo contractual ${ }^{29}$, Pero en prácticamente todas ellas explícita o implícitamente encontramos la idea de evolución. Se trata de una «idea-fuerza» que por su potencia y racionabilidad se impone con suma facilidad haciendo incluso oscurecer valiosas ideas que no llegan a desarrollarse. Para terminar, decir que hoy, en el siglo XXI, en 2011, encontramos confirmado reconocimiento a las ideas de Darwin y su teoría de la evolución al leer afirmaciones como la que sigue: «La visión evolucionista de las cosas, que hoy está perfectamente integrada en nuestra vida cotidiana y hasta en la cultura popular,..... ${ }^{30} \mathrm{o}$ : «Ciento cincuenta años después de la publicación de El origen de las especies, la teoría de la evolución es enseñada en los centros educativos de todo el mundo. La enseñanza de la evolución es incuestionable desde una perspectiva científica y formativa y debe ser parte integral de todo el sistema educativo» (Revista Temas para el Debate, 2011: 33).

\section{Bibliografía}

Aron, R. (1976): Las etapas del pensamiento sociológico, Editorial Siglo Veinte, Buenos Aires. Ayala, J. (2007): Darwin y el diseño inteligente. Creacionismo, cristianismo y evolución, Alianza Editorial, Madrid.

BuRY, J. B. (1928): The idea of progress: an inquiry into its origin and growth, Mac Millan, Londres.

Comte, A. (1943), «Discurso sobre el espíritu positivo», en Comte, A., Breviarios del pensamiento filosófico, Editorial Sudamericana, Buenos Aires.

Comte, A.(1943), "Curso de filosofía positiva, lección 57ª, en Coмte, A., Breviarios del pensamiento filosófico, Ed. Sudamericana, Buenos Aires.

Cosentini, F. (1911): Ensayo sobre el pensamiento y la vida social prehistóricas, Daniel Jorro, Madrid.

Darwin, СH. (1980): El origen de las especies, Ed. Bruguera S. A., Barcelona. Darwin, CH. (1975): Teoría de la evolución, Ed. Península, Barcelona. Darwin, CH. (1995): El origen del hombre, M.E. Editores, S.L., Madrid. Diccionario soviético de filosofía (1965), Ed. Pueblos Unidos, Montevideo.

Dilthey, W. (1949), Introducción a las ciencias del espíritu, F. C. E., México, Buenos Aires. Dubos, R. (1976): Los sueños de la razón. Ciencia y utopías, Breviarios del F. C. E. México. Ferrater Mora, J. (1994), «Evolución y evolucionismo» en Diccionario de Filosofía versión electrónica http://www.ferratermora.org/ency_concepto_de evolucion.html)

Freyer, H. (1945), Introducción a la Sociología, Ediciones Nueva Época, Madrid.

FouilléE, A. (1903), Bosquejo psicológico de los pueblos europeos, Editorial Daniel Jorro, Madrid.

29 «La conciliación de las dos ideas de organismo y de contrato en la de organismo contractual, nos ha llevado de un modo natural a considerar ese problema tan interesante en Sociología como en filosofía de la historia, cual es el de la conciencia social» (FouilLÉE, 1894: 395).

30 Baquedano, E., El triunfo de Darwin, Rev. Temas para el debate, op. cit. p. 22. 
Fouillée, A. (1894), La ciencia social, La España Moderna, Madrid. GaupP, O. (1930), Spencer, Revista de Occidente, Madrid.

Giner De los Ríos, F. (1904), Filosofía y Sociología, Imprenta de Henrich y Ca Editores, Barcelona.

GINER DE Los Ríos, F. (1923), La persona social. Estudios y fragmentos, Editorial Espasa Calpe, S.A., Madrid, Tomo I.

Menéndez Pelayo, M. (1892), «De rerum natura» en Obras escogidas literarias y manuscritos y raros con un estudio crítico biográfico del Dr. D. Marcelino Menéndez Pelayo, Sevilla.

GinsBerg, M. (1961), «El concepto de evolución en Sociología», en Ensayos de Sociología y Filosofía Socia, Editorial Aguilar, Madrid.

González Seara, L. (1976), La Sociología aventura dialéctica, Editorial Tecnos, Madrid. Marías, J. (1978): Historia de la filosofía, Biblioteca de la Revista de Occidente, Madrid. Martindale, D. (1968): La teoría sociológica, Editorial Aguilar, Madrid.

Martínez MarzoA, F. (1975): Historia de la Filosofía, Editorial Aguilar, Madrid Montesquieu, (1980), Del espíritu de las leyes, Editorial Tecnos, Madrid. NisBert, R. (1996): Historia de la idea de progreso, Ed. Gedisa, Barcelona.

Revista Temas para el Debate (2011), Num. 196, Ed. Iniciativas Editoriales Sistema, Madrid. Turgot, A. R. J. (1991), Discursos sobre el progreso humano, Ed. Tecnos, Madrid.

Sales y Ferré, M. (1912), Sociología general, Librería General de Victoriano Suárez, Madrid. Sorokin, P. (1951): Teorías sociológicas contemporáneas, Ed. Desalma, Buenos Aires.

Spencer, H. (1947), Abreviatura de Principios de Sociología, Revista de Occidente Argentina, Buenos Aires.

TimashefF, N. S. (1961), La teoría sociológica. Su naturaleza y desarrollo, Fondo de Cultura Económica, México-Buenos Aires.

White, A. (1982), La ciencia de la cultura. Un estudio sobre el hombre y la civilización, Editorial Paidós, Barcelona.

Wilson, E. O. (1980), Sociobiología. La nueva síntesis, Editorial Omega, Barcelona.

Wilson, E. O. (1999): Consilience. La unidad del conocimiento, Galaxia Gutenberg, Círculo de Lectores, Barcelona.

Wilson, E. O. (2012), La conquista social de la tierra, Debate, Barcelona.

Universidad Nacional de Educación a Distancia, Madrid, GETS

msanchez@poli.uned.es

Hilde SÁnchez Morales

[Artículo aprobado para publicación en diciembre de 2014] 